\title{
A comunicação visual de bulas de remédios: análise ergonômica da diagramação e forma tipográfica com pessoas de terceira idade ${ }^{2}$
}

\author{
The visual communication of medicine information leaflets: ergonomic analysis of \\ page layout and typography for the elderly
}

comunicação visual; ergonomia; bula de remédio

\begin{abstract}
A comunicação visual é o meio necessário para transmissão de informações. Considerando-se que as bulas de remédios oferecem dificuldades de legibilidade para o consumidor da terceira idade propõe-se uma análise de sua composição gráfica da bula de remédio feita por investigação ergonômica textual quanto à sua adequação tipográfica e de diagramação. O estudo realizou pesquisa descritiva com análise da bula de medicamento e de duas coletas de dados por entrevista individual com pessoas acima de 65 anos. A análise da bula do Medicamento $X$, conforme fatores de legibilidade, apresenta inadequação quanto à confusão entre letras e seu tamanho reduzido para a distância de leitura que são combinados com as alterações visuais do envelhecimento. A primeira coleta confirma essas dificuldades de leitura da bula do Medicamento X. A segunda coleta de dados consistiu da apresentação da bula do Medicamento X comparada com dois modelos que se diferenciaram quanto à tipografia - Arial e Times New Roman, porém, com uma mesma diagramação, obedecendo os fatores de legibilidade de texto de Dull (1995). Os resultados de melhor legibilidade para a bula indicam o modelo com tipo Arial. Conclui-se pela necessidade de equilíbrio entre diagramação e tipografia para uma comunicação visual de bulas de remédios.
\end{abstract}

\section{visual communication; ergonomics; medicine information leaflet}

Visual communication is the necessary manner in which to transmit information. Taking into account that medicine information leaflets present legibility difficulties for elderly consumers, an analysis was carried out, by means of a textual ergonomic investigation with regard to typography and page layout adequacy. A descriptive research was conducted through the analysis of medicine information leaflets and of two data collections of individual interviews with people over sixty five years of age. The analysis of the medicine information leaflet of Medicine $X$, revealed that the legibility factors proved inadequate due to the confusion of letters, their reduced size and reading problems linked to sight alterations of growing old. The first data collection confirms these reading difficulties; the second presents the Medicine $X$ information leaflet compared with two different typefaces - Arial and Times New Roman. However, the same page layout was maintained,following the legibility factors from Dull's (1995) text. The results indicate that the typeface Arial provides better legibility. It can be concluded that there is a need for a balance between page layout and typography in the visual communication of medicine information leaflets.

\section{Introdução}

A comunicação visual é o tema principal deste artigo, considerado meio necessário para transmissão de informações. A bula de remédio é imprescindível na vida do cidadão, principalmente, para os da terceira idade que são consumidores habituais deste documento técnico de consulta pública cujo texto possui uma forma de diagramação e tipografia características.

No entanto, sob ponto de vista da área de comunicação visual, observa-se que as bulas de medicamentos, apesar de apresentarem todas as informações necessárias ao usuário, conforme Portaria n.110 (Brasil, 1997), expedida pela Agência Nacional de Vigilância Sanitária, órgão do Ministério da Saúde, sua composição textual quanto aos aspectos tipográficos e de diagramação apresentam os seguintes problemas: tamanho da fonte, espaçamento entre as linhas do texto, organização textual, uso maciço de negrito e outros.

Tais problemas, acarretam dificuldade visual relacionada à incompreensão do texto e cansaço da vista do leitor, razão pela qual o texto da bula de remédio, destinado à informação técnica do farmacêutico, do médico e, principalmente, do leigo, necessita de investigação quanto à sua adequação ergonômica visual. No caso do leitor leigo de terceira idade, principal consumidor de medicamentos, sua acomodação visual deficitária torna ainda mais difícil a visualização e compreensão da informação de bulas de remédios.

Tendo isso em vista, propõe-se uma análise da composição gráfica da bula de remédio feita por uma 


\section{Infodesıgn}

investigação ergonômica quanto a sua adequação tipográfica e de diagramação, direcionado ao leitor de bula de remédio da terceira idade.

A partir desta proposta, tem-se como objetivo realizar estudo ergonômico de comunicação visual da bula de remédio como documento informacional mediante coleta de dados com pessoas da terceira idade a fim de propor adequações de tipografia e diagramação.

A colaboração da tipografia e diagramação apresentadas em uma forma ergonômica correta no conteúdo de um texto informacional importante e necessário como o da bula de remédio que é fundamental à saúde do cidadão, facilita a visualização e compreensão textual pelo consumidor de terceira idade.

\section{Pressupostos teóricos iniciais}

No universo da comunicação visual, existem várias possibilidades de se transmitir informação, como é esclarecido em significado dicionário: ' ... por meio de métodos e/ou processos convencionados, quer através da linguagem falada ou escrita, quer de outros sinais, signos ou símbolos, quer de aparelhamento técnico especializado, sonoro e/ou visual.' (Ferreira, 1975: 356).

A comunicação escrita é um meio fundamental para a disseminação da informação visual, colocando em foco a forma textual, que é transmitida por uma linguagem gráfica. Sendo assim, o design gráfico está intimamente ligado à transmissão da informação textual, para o que Okida (2002) considera que, '...é do design gráfico grande parte da responsabilidade de uma perfeita comunicação entre o impresso e seu público.'

Neste sentido, a utilização dos recursos do design gráfico para melhorar a qualidade e legibilidade da leitura em textos informacionais faz parte da sua configuração comunicativa visual, aplicando-se então, uma visão ergonômica sobre a forma textual. A ergonomia tem por definição a '...pratica do aprendizado sobre características humanas visando a utilização desse aprendizado para melhorar a interação das pessoas com as coisas que elas usam e com os ambientes nos quais elas fazem isto.' (Wilson, 1995 apud Rio \& Pires, 2001:30)

Pelo olho humano é feita a percepção de informações visuais apoiada em uma série de fatores como afirma Dull (1995: 56), 'A forma como são apresentadas essas informações deve ser adequada, tanto quanto possível, à capacidade de percepção dos olhos.' Esta citação condiciona a forma de apresentação textual, como principio básico da ergonomia visual, à percepção de informações visuais.

Os fatores que colaboram com a legibilidade de um texto, indicados por lida (1978: 202), são 'Os tamanhos, proporções e cores usadas em letras, números e símbolos influem na sua legibilidade.' Dull (1995) indica os seguintes fatores:

- Evite textos apenas com letras maiúsculas;

- Os alinhamentos à direita não devem deixar espaços em branco;

- Os tipos de letras sem muita ornamentação são mais legíveis;

- O tamanho recomendado para as letras depende da distância de leitura;

- As linhas longas exigem maior espaçamento entre elas;

- O contraste apresenta influência maior que a iluminação na legibilidade.

\section{Metodologia}

O estudo ergonômico de comunicação visual da bula de remédio como documento informacional é uma pesquisa descritiva que consistiu de estudo de caso com análise de bula de medicamento e de duas coletas de dados por entrevista na cidade de Curitiba.

A análise tomou como estudo de caso a bula do Medicamento $X$ aplicando os fatores de legibilidade de texto de Dull (1995) já mencionado no referencial teórico. O conteúdo técnico deste documento possui uma forma de apresentação gráfica visual característica de bula conforme Portaria n.110 (Brasil, 1997). Partindo desta constatação, a análise da bula do medicamento, que

denominamos de X, realizada conforme fatores de legibilidade apontados por Dull (1995), apresenta adequação aos fatores de: evitar uso de textos apenas de letras maiúsculas; textos que

se alinham pela margem direita não devem deixar espaços em branco; e uso de letras simples. 
Quanto aos pontos que não se adaptam à forma adequada de legibilidade se enumeram na confusão entre as letras, devido ao tamanho inadequado de letras em relação à distância de leitura, espaçamento reduzido entre linhas e a característica do papel translúcido que diminui o contraste. A bula do Medicamento X utiliza fonte Arial, corpo 5, alinhamento justificado, espaçamento reduzido entre linhas, letras e parágrafos.

A primeira coleta de dados teve como objetivo confirmar a existência de dificuldade na leitura por 10 pessoas, homens e mulheres acima de 65 anos de idade, quando a forma tipográfica e de diagramação da bula de medicamento apresentavam problemas de comunicação visual. Foram utilizadas nesta coleta 4 bulas de diferentes medicamentos que denominamos de Medicamentos $\mathrm{V}, \mathrm{W}, \mathrm{X}$ e $\mathrm{Y}$.

A segunda coleta de dados, com o objetivo de observar as formas de diagramação e tipografia mais adequadas à legibilidade de bulas de medicamentos, consistiu da apresentação da bula do Medicamento $X$ comparada com dois modelos que se diferenciaram por formas tipográficas e de diagramação em entrevistas individuais com 10 sujeitos, homens e mulheres, acima de 65 anos de idade.

A elaboração dos modelos seguiu dois padrões quanto à tipografia - Arial e Times New Roman, considerados tipos clássicos, e um mesmo padrão quanto à diagramação - conforme os fatores de legibilidade de texto de Dull (1995), obtendo-se, assim, os dois modelos abaixo:

- Modelo 1: Arial (fonte sem serifa, corpo 8) com os fatores de legibilidade de texto; Modelo 2: Times New Roman, (fonte com serifa, corpo 8) com os fatores de legibilidade de texto;

Para adequar o tamanho das letras à distância de leitura, nos modelos utilizamos 1,8 mm para altura da letra, considerando a proporção de 1/200 mm de distância para a leitura recomendada por lida (1978) e Dull (1995). O espaçamento entre palavras teve 1,6 mm considerando a proporção de 1/30 mm com o tamanho da linha.

\section{Resultados e discussão}

As pessoas da terceira idade apresentam certas alterações visuais que, segundo Gomes (1995), aparecem durante o seu envelhecimento, como a presbiopia, que se caracteriza como diminuição da capacidade do cristalino em enfocar diferentes distâncias; catarata que é decorrente da opacificação do cristalino; e a degeneração macular senil, traduzindo-se como alterações isquêmicas da retina, que se acentuam com idade.

Retomando o estudo de caso da bula do Medicamento X, considera-se que a não adequação dos fatores de legibilidade, principalmente, de confusão entre as letras e tamanho reduzido de letras para a distância de leitura serão combinados com as alterações visuais do envelhecimento.Com aumento do tamanho da fonte tipográfica e melhor espaçamento entre linhas, facilitaria a leitura para os idosos que usam lentes focais ou multifocais. Os resultados da primeira coleta confirmam essas dificuldades de leitura da bula do Medicamento $X$ e do Medicamento $\mathrm{Y}$, o que não ocorreu com os medicamentos $\mathrm{V}$ e $\mathrm{W}$ por apresentarem maior adequação aos fatores de legibilidade de Dull (1995).

Foram realizadas entrevistas com 10 pessoas da faixa etária de 66 a 76 anos utilizando os dois modelos de bula que se diferenciavam pela fonte Arial (sem serifa) e Times New Roman (com serifa) ambas com corpo 8 e com adequações feitas em sua diagramação como: espaçamento entre palavras de acordo com o comprimento da linha e alinhamento de texto à esquerda. Obtivemos como resultado, para melhor legibilidade, a indicação de cem por cento para o modelo 1 de tipo Arial, mostrando que a fonte sem serifa é mais legível do que a com serifa e quanto à diagramação, no que se refere a espaçamento entre linhas e palavras e alinhamento à esquerda, tais fatores são fundamentais para facilitar a leitura do texto. Esses resultados reforçam a necessidade de equilíbrio entre diagramação e tipografia para uma comunicação visual de bulas de remédios.

\section{Considerações finais}

O estudo ergonômico de comunicação visual da bula de remédio realizou análise da composição gráfica da bula de remédio e investigação ergonômica quanto à sua adequação 


\section{Infodesıgn}

tipográfica e de diagramação para o leitor de terceira idade tendo como parâmetro teórico e metodológico os fatores de legibilidade de Dull que propiciaram a elaboração de dois modelos de bula contendo, em sua proposta, uma combinação equilibrada de adequação tipográfica e de diagramação.

A partir dos subsídios teóricos e metodológicos e análise comprovada de cem por cento dos entrevistados na coleta de dados realizada com os modelos de bula, foi demonstrado que a fonte Arial apresentou resultado positivo, de corpo 8 (altura 1,8mm), 50mm de comprimento de linha, 1,6 $\mathrm{mm}$ de espaçamento entre palavras, $3 \mathrm{~mm}$ de espaçamento entre linhas e alinhamento de texto à esquerda.

\section{Referências}

Brasil. Ministério da Saúde. Portaria n.110, de 10 de março de 1997. Disponível em: http://www.anvisa.gov.br/legis/portarias/110_97.htm. Acesso em 06 de março de 2004.

Dull, J. (1995) Ergonomia prática. São Paulo: E.Blücher.

Ferreira, A. B. de H. (1975) Novo dicionário da língua portuguesa. Rio de Janeiro: Nova Fronteira.

Gomes, F. A. de A., \& Ferreira, P. C. A. (1985) Manual de geriatria e gerontologia. Rio de Janeiro: EBM- Editora Brasileira de Medicina.

lida, I. (1978) Ergonomia. 3ed. São Paulo: Faculdade de Engenharia Industrial.

Okida, M. (2002) O design gráfico como elemento de linguagem editorial. DesignGráfico, abr.

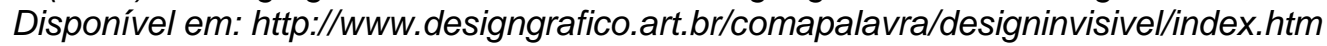
Acesso em 06 de março de 2004.

Rio. R. P., \& Pires. L. (2001) Ergonomia: fundamentos da pratica ergonômica. São Paulo: LTr

Sarde, C. L. (2003) Análise diplomática de bulas de medicamentos: um cotejo entre as dimensões normativa e técnica. Trabalho de conclusão de Curso (Biblioteconomia) Faculdade de Filosofia e Ciências, UNESP.

\section{Sobre a autora}

Patrícia Tiemi Lopes Fujita é aluna no Curso de Desenho Industrial - Comunicação Visual da Pontifícia Universidade Católica do Paraná - PUC, em Curitiba. 